\title{
isions
}

Revista Educación

ISSN: 0379-7082

ISSN: 2215-2644

revedu@gmail.com

Universidad de Costa Rica

Costa Rica

\section{Significados sobre política educativa desde la perspectiva del profesorado de educación obligatoria y superior en México}

\section{Cruz Vadillo, Rodolfo}

Significados sobre política educativa desde la perspectiva del profesorado de educación obligatoria y superior en México

Revista Educación, vol. 45, núm. 1, 2021

Universidad de Costa Rica, Costa Rica

Disponible en: https://www.redalyc.org/articulo.oa?id=44064134010

DOI: https://doi.org/10.15517/revedu.v45i1.40597

\section{(c) (1) $\Theta \Theta$}

Esta obra está bajo una Licencia Creative Commons Atribución-NoComercial-SinDerivar 3.0 Internacional. 


\title{
Significados sobre política educativa desde la perspectiva del profesorado de educación obligatoria y superior en México
}

\author{
Understanding Educational Policy in Mexico from a Compulsory and Higher Education Teachers' Perspective
}

Rodolfo Cruz Vadillo

Universidad Popular Autónoma del Estado de Puebla,

México

DOI: https://doi.org/10.15517/revedu.v45i1.40597

Redalyc: https://www.redalyc.org/articulo.oa?

rodolfo.cruz@upaep.mx

(iD http://orcid.org/0000-0002-2561-1559 $\mathrm{id}=44064134010$

Recepción: 13 Marzo 2020

Aprobación: 24 Agosto 2020

\section{Resumen:}

Este trabajo es fruto de una investigación cuyo propósito fue analizar los significados que el profesorado ha construido sobre la categoría de política educativa. La perspectiva teórica de este trabajo se encuentra relacionada con un posicionamiento de la política educativa como campo de conocimiento, atravesado por lo político y dirigido a la constitución de identidades sociales. El método fue cualitativo, interpretativo de alcance descriptivo. La técnica utilizada fue el cuestionario, y el tratamiento hacia los datos se basó en un análisis de discurso. Los participantes fueron 90 docentes de educación obligatoria y superior de la ciudad de Puebla. Las principales conclusiones refieren a una visión restringida de la política educativa, la cual no recupera lo problemática, compleja y conflictiva que es la realidad educativa, además de ubicarse escasamente relacionada con las subjetividades y creencias del profesorado en materia educativa y como principal promotor del proyecto ético- político. La situación puede tener varias implicaciones, por un lado, la falta de reconocimiento de la labor docente como aquellos sujetos que aterrizan la propuesta política en educación, lo cual puede ser un impedimento para el logro de los propósitos educativos; por otro, la pasividad que al parecer se ha establecido entre el profesorado en la relación política-docencia, la cual es una visión restringida de la labor de estos profesionales y por tanto minimiza el impacto que tienen desde los espacios institucionalizados.

Palabras Clave: Política educativa, Docentes, Significados, Biopolítica, Educación obligatoria, Educación superior.

\section{Abstract:}

This study analyzes the various meanings that teachers have incorporated into the subject of educational policy. Theoretical perspective position educational policy as a cross-cutting field involving politics and aimed at constructing social identity. The methodology was qualitative, interpretative and descriptive. The techniques employed was a questionnaire and data processing were based on discourse analysis. The study participants included 90 compulsory and higher education teachers in the city of Puebla. Based on the conclusions, educational policies have a restricted scope that do not resolve the problems, complexities and conflicts of actual educational scenarios and is not aligned to the subjectivities and beliefs of the faculty when dealing with educational matters and in their role as the main ethical-political proponents. This situation may lead to several consequences: the role of teachers will not be acknowledged as enforcers of educational policies, which can be an obstacle to achieving educational goals. Furthermore, teachers may be viewed as too passive with regards to politics and teaching, which is a limited view of their duties as experts and, thus minimizes the impact they may have in their role.

KeYwORDS: Educational Policies, Teachers, Meanings, Biopolitics, Compulsory Education, Higher Education.

\section{LA POLÍ́TICA EDUCATIVA: UN ESPACIO PARA SU PROBLEMATIZACIÓN}

La revisión de la literatura permite ver que en las últimas décadas se ha dado una proliferación de estudios y artículos sobre el tema de política educativa, los cuales, en general, retoman algunas temáticas centradas sobre todo en lo concerniente a la democratización de lo educativo, los procesos de reforma, el impacto de las políticas internacionales, entre otros temas que implican una discusión solo a nivel óntico (Carlachiani, 2017; Compromiso Social por la Calidad de la Educación, 2015; Laboratorio Latinoamericano de Evaluación y 
Calidad de la Educación, 2016; Razo, 2018), es decir, los objetos de estudio están ubicados en propuestas, acciones y documentos que de una u otra forma se consideran como dados y por tanto, el trabajo investigativo, aunque es valioso, corre el peligro de quedarse en la revisión del contenido y la declaración de las valoraciones en torno a los logros de estos, sin discutir las formas en que dicha realidad política se ha constituido como tal.

En otra óptica investigativa, la escasez está en trabajos que den cuenta de otras discusiones que pudieran ser planteadas desde cuestiones ontológicas y epistemológicas sobre el estado que guardan esos tópicos y su relación con la educación, en específico lo escolar, pero sobre todo con docentes y su formación profesional (Fernández, 2018; Juárez, 2014; Álvarez, 2018, Martínez, 2018; Alarcón y Donoso, 2018). El presente texto pretende ser una aportación en este último sentido.

El aumento de estudios sobre el tema en los últimas décadas (Latapí, 2004;Tello, 2015; Flores, 2009; Treviño, 2015), ha dado la posibilidad de pensar la política más allá de una concepción desde la expertise, es decir, se ha hecho presente un ejercicio de descentración, en donde dicha temática era abordada y problematizada por aquellos que estaban en el campo político y que incluso tenían una relación cercana a este; permitiendo un ejercicio analítico de desmontaje, resignificando las creencias y conceptos (ontológico). Referir la política educativa como un asunto que concierne a sujetos que se encuentran en las esferas de poder gubernamental ha imposibilitado una participación desde un matiz democrático, abonando al interés por el tema (Treviño, 2013; Fuentes, 2019).

En este marco, uno de los sujetos que se ha quedado al margen, a pesar de ser el encargado de llevar a cabo el proyecto ético-político nacional, ha sido, entre otros agentes, el profesorado de la escuela pública en México, cuyo papel en el plano político casi es impensable a no ser que se relacione con temas sindicales, quedando al margen de las discusiones, las decisiones, los posicionamientos teóricos y pedagógicos que obligatoriamente le importan e incuben. Lo cierto es que, la política educativa, no solo es un conjunto de normas, disposiciones, ordenamientos y leyes que solo interesan a unos cuantos, también es un campo de estudio y de conocimiento (Tello, 2015) y, es desde esta perspectiva, que se hace necesario un posicionamiento que la relacione no solo con dimensiones prácticas y técnicas, sino también con problemas tanto epistemológicos como teóricos. Por si esto no fuera suficiente, la política educativa se diferencia de otras manifestaciones de política pública, precisamente por su componente educativo lo cual la inscribe forzosamente en los debates epistémicos y teóricos contemporáneos, sobre todo en los que concierne a los fines de la educación y por ende de la escuela.

Lo educativo está atravesado por una serie de tensiones fruto de imbricaciones e intercambios simbólicos de elementos contextuales, históricos, sociales, culturales y económicos (Cruz, 2008). Por su parte, la política es un lugar también problemático, atravesado por el conflicto y lo político (Treviño y Tolentino, 2017; Fuentes, 2019. Este caldo de cultivo, cuando aterriza en el terreno de lo educativo, activa un juego de interpelación e identificación que posibilita la constitución de identidades en lo social, en este caso del profesorado encargado de llevar a cabo el proyecto desde las aulas y escuelas (Buenfil, 1993, 2018).

La política educativa, desde esta deferencia, es un proceso de gubernamentalización, como Foucault (2006) lo entiende, un espacio de gobierno de los sujetos, de sus subjetividades, pero además es una biopolítica puesto que se incorpora en las propias estructuras cognitivas, que conforman formas de ver y de estar en el mundo y por ende, de relacionarse, de pensar y de conducirse.

Desde este marco de referencia, se cree necesario emplazar una mirada analítica que no solo desarrolle una revisión conceptual y teórica, sino que permita observar y dar cuenta de las formas en que la categoría de política educativa ha sido traducida por determinados agentes, por ejemplo, el cuerpo docente (Cruz, 2008), dicho ejercicio puede posibilitar pensar, desde un plano formativo, cómo ha sido tratado el tema y qué papel juega en su vida profesional.

Este trabajo pretende abordar un análisis, no de la política educativa en sí, tampoco de lo que la ciencia política o la filosofía política han intentado teorizar y concretizar conceptualmente, más bien, su mirada analítica se aproxima a las construcciones simbólicas que el profesorado ha internalizado en torno a este 
significante. El objeto de estudio a abordar tiene que ver con los significados que cada docente ha construido sobre la política educativa; su objetivo es analizar dichos significados en torno a esta categoría.

Este estudio tuvo como propósito contestar a la siguiente pregunta: ¿cuáles son los significados que el profesorado ha construido sobre la política educativa?, para aproximarse a esta primera cuestión se han pensado otras preguntas que sirven de apoyo analítico: ¿cuál es el lugar y función que el propio profesorado identifica que tiene en el campo de la política educativa?, ¿cuáles son las relaciones que ha construido el profesorado sobre la política educativa y lo educativo-pedagógico? y ¿cuál es el papel que juega la política educativa en su labor como docente? Para aproximarse a las interrogantes anteriores, en concreto, este texto parte de dos cuestiones centrales: 1) identificar los bienes simbólicos que el personal docente relaciona con la política educativa y 2) señalar las formas y lógicas de implementación que son reconocidas por este.

Esta investigación se justifica desde distintos ámbitos, por un lado, este tipo de estudio puede aportar teóricamente a comprender las formas en que interacciona la política educativa con el profesorado y su propia materialización en prácticas determinadas.

Políticamente es interesante, pues permite dar cuenta de las formas de conocimiento que lo dispuesto en los documentos se han traducido en determinadas maneras de comprender cuestiones como la enseñanza y la docencia.

Personalmente, este trabajo permite analizar de cerca una práctica como docente de política educativa y la relevancia que tiene la asignatura, no solo para tener una mirada comprensiva del funcionamiento y estructura de un sistema educativo, sino también de los sistemas de razón y lógicas que se ponen en juego en todo el aparato político-educativo.

Por otra parte, su relevancia se puede pensar a partir de una serie de implicaciones que son importantes de abordar; en un primer momento, la falta de reconocimiento de la labor del profesorado como aquellos sujetos que aterrizan la propuesta política en educación, lo cual puede ser un impedimento para el logro de los propósitos educativos; en otro, la pasividad que al parecer se ha establecido entre docentes en la relación política-docencia, la cual es una visión restringida de la labor de estos profesionales y por tanto minimiza el impacto que tienen desde los espacios institucionalizados.

Lo anterior no es solo un asunto que impacte a nivel escolar y didáctico, sino que también tiene consecuencias políticas, en el sentido de que si la educación es un medio para garantizar estados de bienestar, su materialización como práctica y ejercicio no puede quedar lejana en la formación del profesorado.

\section{Perspectiva teórica}

\subsection{La política educativa como campo de estudio}

Tello (2015) menciona que el campo de la política educativa, como espacio de estudio y discusión epistemológica y teórica, es relativamente nuevo, la centralidad del tema se ha sesgado por una visión más técnica e instrumental. En México, por ejemplo, la política educativa se ha pensado más bien desde la lógica de la política pública; en este sentido, Aguilar $(2004,2007)$ ha sido uno de los fuertes exponentes de las formas en cómo se entiende la política en general.

Para Aguilar (2004, 2007), la política pública, desde una perspectiva, tiene que ver principalmente con un proceso lógico y racional, en donde existen una serie de pasos a seguir que pueden permitir el análisis, hechura e implementación de las políticas en general, aunque este autor no habla específicamente de políticas educativas, dicha visión ha permeado la forma de comprenderlas desde el ámbito educativo. Por ejemplo, el profesorado entiende que la política tiene una fase de diseño, implementación y evaluación, similar al ciclo de políticas ya señalado. 
Sin embargo, como ya se ha apuntado líneas atrás, la política educativa no solo tiene que ver con un procedimiento que sirve de instrumento para la ejecución y valoración de acciones en lo público, también es un campo en el sentido más estricto, como lo entiende Bourdieu (2002), conformado por una serie de disposiciones y estructuras que interaccionan y se relacionan entre sí, además, se encuentra atravesado y sobredeterminado por una serie de principios explicativos y formas de conocimiento (Popkewitz, 1994,1997, 1998, 2009; Popkewitz y Brennan, 2000) que le dan contenido teórico.

Para Tello (2015), el campo de la política educativa debe verse como un espacio ontológico, epistemológico y teórico que no es simple, sino más bien implica una complejidad que no se agota en su parte formal (ley), tampoco en el plano de la acción (política pública). Desde esta perspectiva, el tema merece un análisis que implica un referente teórico y un ejercicio más de índole científico que político (en su forma más técnica y práctica de entender).

Un ejemplo interesante de esta mirada se encuentra en los trabajos desarrollados por la Red de Estudios Teóricos y Epistemológicos de Política Educativa (Relepe), en donde a partir de una interesante contribución científica, se ha puesto sobre la mesa el papel de la política educativa en la escena escolar, argumentando que su estudio debe ser abordado no solo como un ejercicio netamente racional, sino como un espacio en donde las singularidades, las representaciones, los subjetividades se encuentran bajo una guía epistemológica y teórica que debe ser reconocida más que obviada.

La política educativa como campo de conocimiento implica una revisión de sus fundamentos, de los tipos y formas de conocimiento que la produce y las formas de prácticas que ella misma genera. Por tanto, la revisión de sus perspectivas onto-epistemológicas son la condición de posibilidad para permitir la mirada analítica de esta (Giovine y Suasnábar, 2012). Significa, además, la vuelta a las teorías tanto generales como sustantivas que la constituyen (Tello, 2015). Por otro lado, tiene que ver con los efectos, entendidos como nuevas sujeciones que impactan las identidades de a quienes está dirigida y ejecutan los complejos procesos de traducción.

Mainardes (2015) menciona que el objeto de estudio de la política educativa no es un elemento tan claro y preciso que haga posible delimitarlo de una vez y para siempre. Más bien, el espacio simbólico que rodea este significante es abierto y amplio en espectro. Dicho autor señala algunas de ellas:

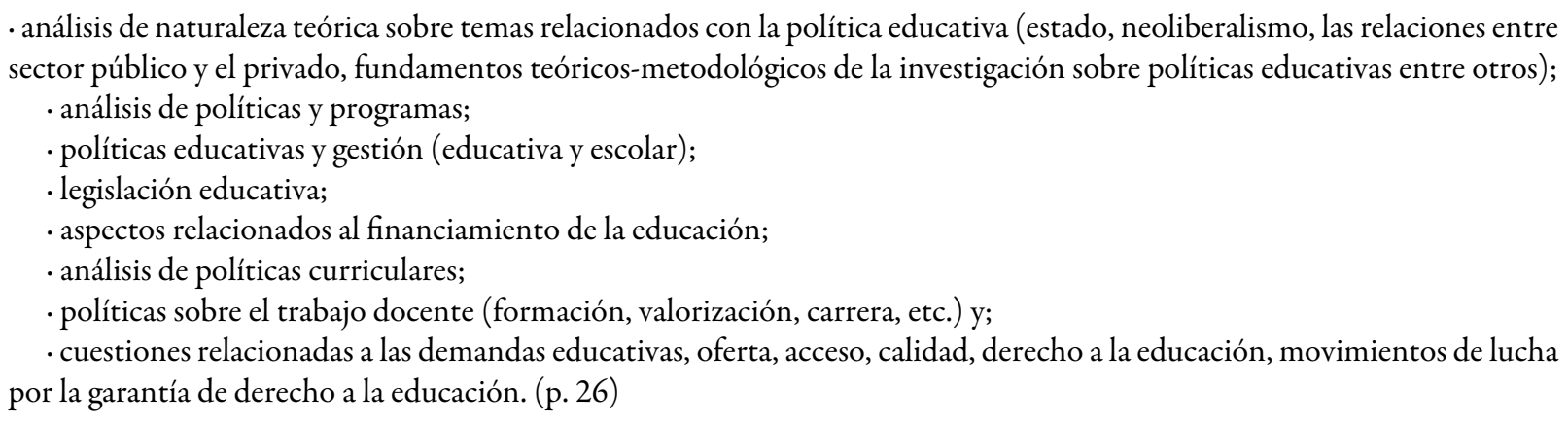

Si bien todo hace referencia a la política educativa, en algunos aspectos el énfasis está dado más en el plano de la acción, de la concreción, en documentos y procesos objetivados que indican guías o pautas de conducción frente a un determinado fenómeno. Por otro lado, se señalan elementos más abstractos y simbólicos, es decir, más teóricos que utilitarios. Cuestiones donde el poder, las relaciones, los conflictos, las rupturas, los desencuentros son cotidianos. La política educativa vista de esta forma puede ser considerada un espacio de lucha y debate en torno a una determinada problemática, la cual es compleja como lo es lo social.

Tello (2015), partiendo de esta complejidad, dice que "debemos considerar que de algún modo las regulaciones internas en el campo de la política educativa se estructuran en base a su relación con otros campos de estudio [...]" (p. 48). En este sentido, los objetos de estudio de la política se encuentran también traslapados desde otros referentes, territorializados por significaciones, valores y epistemes de época (Foucault, 2006).

En línea con lo anterior, la política educativa más que ser vista desde una estructura de árbol (arborescente), tendría que pensarse en clave rizomática (Deleuze y Guattari, 1994), donde complejas relaciones intersticiales 
se dan en un determinado espacio de lo social (Tello, 2015), negando que su lógica y estructura responden a una visión lineal con dirección definida, sino más bien a una serie de ciclos, idas y venidas, encuentros y desencuentros que están constantemente estructurando las relaciones político-sociales.

En este marco, son variadas las perspectivas desde las cuales se puede pensar la política educativa, sin embargo, para fines analíticos, este trabajo se posicionará desde tres miradas: a) la comprensión de lo político como figura de análisis que puede posibilitar la explicación sobre el papel del conflicto en el espacio social; b) la política educativa como proceso de gubernamentalidad que la entiende más allá de la ley, pensándola más bien en las formas de gobierno de los sujetos y no solo de las cosas en abstracto; por último, c) la idea de pensar la política educativa en clave biopolítica, la cual permite profundizar en las formas de subjetivación e internalización en el mundo de vida de aquellos sujetos que son sujetos de la misma.

\subsection{Lo político en la política educativa}

Como ya se había anotado en líneas anteriores, la política educativa, vista desde el enfoque de la política pública ha privilegiado una mirada técnica $y$, al hacerlo, ha permitido pensarla como una cuestión que principalmente tiene que ver con un tipo de racionalidad la cual puede ser aplicada para la toma de decisiones, donde el objetivo es llegar a acuerdos para seguir el procedimiento que lleva al diseño, implementación y evaluación de ellas (Política Pública). El problema en esta forma de entender la política educativa, es decir, desde esta lógica de política pública, es que niega, por un lado, el contenido propio de esta, así como las tensiones epistemológicas y los debates teóricos que están presentes cuando se construye el tipo ideal de sujeto que la educación debe formar; por otro lado, se niega que en esos encuentros está presente lo político (Treviño, 2013), es decir, se omite que las decisiones que se toman, así como las propuestas que se invisibilizan, no son solo fruto de consensos ampliamente analizados, sino que también están sesgados por los intereses, las visiones propias, las creencias morales y éticas (Ball, 1990), los principios políticos que se siguen, la adherencia a ideologías e incluso perspectivas teóricas determinadas.

En este sentido es necesario efectuar algunas demarcaciones conceptuales que permitan una aproximación al concepto de política que se quiere sostener, tal ejercicio implica una diferenciación entre lo que es la política, y su relación con las políticas (en plural) y lo político. En esta tónica, la política se puede entender como arena y acción:

[...] la política emerge en diferentes lugares y espacios, en diferentes escalas, sus lugares más formalizados son los partidos y las instancias de gobierno, pero también las instituciones como las universidades, que montadas sobre valores, principios y agendas, más o menos específicas, persiguen diferentes objetivos (Treviño, 2015, p. 44).

Hay, entonces, en la política un determinado sistema de valores que mientras incluye a unos, otros son excluidos. En este marco están presentes lógicas de razonamiento, procesos de subjetivación/objetivación, pero también intereses y relaciones de fuerza en diversos sentidos.

La política implica la participación y producción de sujetos y agentes sociales [...]. Es, pues, un lugar y tarea de la lucha por los sentidos, por los espacios, por la distribución del poder y es extensiva e inherente a toda idea de sociedad (Treviño, 2015, p. 45).

Este complejo entramado que representa la política debe materializarse y traducirse en mecanismos e instrumentos concretos, estos son las políticas, entendidas como las formas prácticas (para gobernar y dirigir) que se dan en el encuentro o desencuentro de la arena política. Su fin último es la gestión de los espacios, territorios, significados y representaciones en el espacio simbólico de lo social. Son, en sentido estricto, dispositivos interpelatorios, altamente racionales, que a la vez que objetivan, construyen realidades e ideales de plenitud. 
Por su parte, lo político está relacionado con un plano conflictivo, dimensión que permite pensar que las decisiones en materia de política educativa son tomadas por sujetos cuyas sujeciones y subjetividades les hacen plantearse las diversas problemáticas y fenómenos desde una determinada perspectiva y no otra.

Según Mouffe (1993), lo político está "ligado a la dimensión de antagonismo y de hostilidad que existe en las relaciones humanas, antagonismo que se manifiesta como diversidad de las relaciones sociales" (p. 14). Para Laclau en Treviño (2015):

Lo político se entiende aquí como el momento de institucion/desinstitución de lo social, en el cual, a través de procesos contingentes que permiten procesos articulatorios, lo social emerge y se estabiliza; o debido a acontecimientos de interrupción, ruptura o quiebre $[\ldots]$ se rompe y reactiva $[\ldots]$. (p. 46)

Lo político permite cuestionarse sobre lo ontológico; lo ontopolítico, está íntimamente ligado a la política y las políticas. En este punto de intersección, las políticas producen sujetos, pues son representaciones de cosmovisiones y epistemes de época. Es decir, hay una característica altamente subjetivante.

Para que las políticas puedan entrar a la escena y fijar una ontología, institucionalizando lo social, es necesario dotar de cierta estabilidad (momentánea) y de un orden a determinadas formaciones y prácticas discursivas y sociales. "Para pensar lo político se requiere aceptar un supuesto ontológico base: la realidad se constituye por medio de un juego de estructuraciones y des-estructuraciones marcadas por la contingencia que condiciona la estabilización última de las formaciones sociales" (Treviño, 2015, p. 55).

La propuesta en este trabajo está centrada precisamente en este orden de la política educativa. El profesorado tiende a verla como una estructura que está dada y que hasta cierto punto es neutral y objetiva, puesto que fue fruto del consenso de los encargados de diseñarla, los cuales como sujetos racionales la construyeron pensando en el bien común; además, se encuentra fundamentada desde diversas miradas a lo educativo, las cuales son plausibles para el profesorado, olvidando que dichos posicionamientos son unos entre muchos otros. En otras palabras, la política educativa para el personal docente se presenta casi como un universal, y aunque para algunos es momentáneo, representa la verdad de lo educativo para ese momento concreto tanto histórico, como social, político y económico.

La política educativa se conceptualiza entonces como escasamente problemática, pero sobre todo, como espacio de defensa hacia la mejora y el desarrollo, económico y humano del país, invisibilizando el plano de lo decisional, donde se encuentran los conflictos, intereses, visiones, etc. que se jugaron en el espacio político, y que como todo proceso humano y social, trae como resultado, no la inclusión completa de los sujetos, sino una inclusión parcial en donde algunos pueden quedar comprehendidos pero otros excluidos, en otra palabras, un proceso de inclusión/exclusión.

Todo movimiento, que en un ejercicio hegemónico llega a constituirse como universal, a pesar de ser en principio un particular, deja fuera un excedente que ya no logró contener; dicho espacio posiblemente estará ocupado por sujetos cuyos beneficios políticos no se verán materializados tan fácilmente, frente a otros que seguro lo harán de forma casi inmediata. La política educativa así entendida, más que pensarse en un espacio acabado, que es bueno por naturaleza, puesto que está pensado en las personas, o que es incuestionable, pues estando desde el aparato jurídico es legal y por tanto imperativo moral y ético, debe significarse como un lugar donde habita lo político, y por tanto, la diversidad y diferencialidad, más que la "mismicidad".

Reconocer lo político en la política educativa permite que se active lo democrático (Butler y Laclau, 2008) al plantear un terreno dialéctico, las posturas encontradas para realizar un complejo proceso de síntesis.

\subsection{La política educativa en clave biopolítica: un ejercicio de gubernamentalidad}

Los conceptos que se han construido a partir de la categoría de política educativa son centrales en el sentido que permiten un posicionamiento y claridad en torno a los fines de la acción educativa del profesorado. En este sentido, el conocimiento que se haya construido y las representaciones que se conformen con respecto a 
la esta, son en su totalidad un objeto de estudio plausible de estudiar. La formación que este ha recibido sobre el tema de la política educativa ha estado encaminada a la comprensión y explicación de la norma (Fuentes, 2019), puesto que en la medida que ellos tengan claridad de los fines que se buscan, de la misma forma pueden contribuir a los propósitos ahí planteados. El énfasis ha sido puesto en la ley como marco privilegiado de estudio, sin embargo, aunque esto representa la parte formal de la política, en sentido estricto solo da cuenta de una mínima parte de esta.

El hecho es que, para el profesorado, la política educativa, al estar en el plano legal, sigue colocándose muy alejada de su labor. Si bien para muchos es algo que se puede materializar y concretar en planes y programas de estudio, fundados desde una nueva reforma educativa, la cual permite el acceso a determinadas técnicas y métodos pedagógicos de enseñanza y aprendizaje, la visión hegemónica sigue observándose como solo receptiva, es decir, la política educativa es un instrumento, ley, reforma, etc. que dicta qué es lo que el profesorado debe hacer en el aula y la escuela. En este sentido, parece que la política educativa señala una serie de obligaciones que se deben cumplir a partir de lo dictado.

Como más adelante se verá, la política educativa para el personal docente refiere a instrumentos o dispositivos que organizan y rigen los planes, las leyes, las reformas, los métodos, el aprendizaje, la enseñanza, etc. Sin embargo, en dichas ideas algo se ha obviado, olvidado o invisibilizado. Si la política educativa está atravesada por lo político, y si lo político se puede colocar en el plano de las subjetividades (Padierna, 2017; García, 2017; Juárez, 2013; Cruz, 2011). Resulta que la política educativa organiza, gestiona y regula más que documentos de política. Si el recurso de lo político lleva a pensar la política educativa como una ontopolítica, el resultado de este ejercicio es la organización también de las identidades que se juegan en lo social, en otras palabras, representa un proceso de gubernamentalización del espacio escolar.

En este sentido, la política educativa no solo está dirigida a las normas y documentos, también intenta interpelar a los encargados de ejecutarla, pero no como lo piensa alguna parte del profesorado, es decir, no como meros encargados de seguir los pasos para cumplimentarla, su objetivo es también activar un proceso de interpelación e identificación que permita la autotransformación del sujeto y la constitución de una nueva identidad (Correa, 2011; Ávalos, 2013; Navarrete, 2017).

En este marco es oportuno retomar la categoría de biopolítica propuesta principalmente por Foucault (2007), que invita a pensar al sujeto como sujeto de un discurso político cuyo fin no es la mera transformación de las leyes y documentos, sino la propia transformación. La política educativa les habla a varios agentes, pero centralmente intenta articular su discurso al propio de la autotransformación y, al hacerlo, posibilita intercambios simbólicos entre el deber ser de la política, la realidad y visión de cada docente.

Los documentos de política, como los planes y programas de estudio, son los textos que están dirigidos directamente al cuerpo docente, en ellos no solo se han desplegado una serie de intenciones educativas a nivel nacional, sino también se han construido formas de conocimiento y saberes sobre lo que debe ser lo escolar, sobre cómo es un buen docente (Hernández, 2015; Popkewitz, 1998), también sobre cuáles son las cualidades de un estudiantado ideal. Los documentos de política son presentados como ideales de plenitud a seguir, en donde se han señalado algunas incompletudes, entre ellas, la del propio profesorado, que, frente al texto, se encuentra en falta. Dicha ausencia se puede traducir, por ejemplo, en la necesidad de dominar las nuevas metodologías de enseñanza y aprendizaje, los nuevos fines educativos que responden al contexto de actualidad, las nuevas perspectivas teóricas que están en boga y que permiten aprendizajes auténticos y significativos, las nuevas formas de organización escolar y de gestión, entre muchos otros elementos educativos.

El ejercicio entonces deviene en una interrogación hacia la propia subjetividad, en este caso a la subjetividad e identidad de la persona docente, que frente a los nuevos horizontes, debe replantear su saber y resignificar lo que es como enseñante. En este sentido, no solo se modifican conductas y formas de proceder, sino también se replantea el ser propio de cada docente, cuya actividad de actualización frente a la constante de reformas educativas parece no tener fin. 
La política educativa, en clave biopolítica (Lemke, 2017; Osorio, 2012; Sorrentino, 2012), permite observar que lo dispuesto en ella llega a ser de tal grado que incluso modifica no solo formas de organización, sino también estructuras cognitivas, lo cual permite nuevas sujeciones discursivas y voluntades de verdad que se materializan en formas de ver una realidad, de actuar, de gestionar lo educativo, pero sobre todo de pensarse como sujeto, en este caso como docente.

\section{MÉTODo}

Este trabajo está diseñado desde una perspectiva cualitativa, cuyo alcance es descriptivo. Esta decisión se tomó de acuerdo con la naturaleza del objeto de estudio, que a todas luces se interesa por cuestiones simbólicas, reconociendo que las creencias y significados juegan un papel central para comprender determinados fenómenos sociales. En este sentido, la perspectiva cualitativa, más que posibilitar el establecimiento de relaciones de causa-efecto, permite una mirada comprensiva a las subjetividades, los actos de habla, las representaciones y construcciones a nivel simbólico (Álvarez, 2003).

En este sentido, el método es interpretativo, pues interesó indagar sobre las formas en que el profesorado ha construido un tipo de significado en torno a la política educativa. Desde esta mirada, el ejercicio analítico giró sobre la comprensión de las realidades particulares a partir del contexto y viceversa. Cabe mencionar que de acuerdo con las características del estudio y las particularidades de los datos, se trabajó desde una perspectiva de análisis de discurso con base en una pregunta ordenadora y dos preguntas detonadoras.

La pregunta heurística que guía esta fase constructiva fue la siguiente: ¿Cuáles son los significados construidos sobre política educativa por parte del profesorado? Para poder acceder de forma concreta a dicha pregunta, se establecieron dos interrogantes, cuya función es concretar en categorías los elementos centrales del discurso del cuerpo docente.

¿Cuáles son los bienes simbólicos (traducidos en documentos, valores y formas de ser-actuar) con los que el profesorado relaciona a la política educativa?

¿Cuáles son las formas de materialización desde las cuales el profesorado identifica la política educativa?

La técnica fue un cuestionario cualitativo el cual constó de ocho preguntas abiertas. No obstante, para este trabajo solo se presentan los resultados analizados de dos preguntas de dicho cuestionario, las cuales trataban sobre ¿qué es la política educativa? y ¿cuáles son las características que, de acuerdo con su experiencia, reconoce de una política educativa?

Las personas participantes fueron 90 docentes de educación obligatoria y superior, 68 de género femenino y 22 de género masculino, que cursaban la asignatura de política educativa y gestión escolar del programa de Maestría en Pedagogía de una Institución de Educación Superior de la ciudad de Puebla (Ver Tabla 1). Cabe señalar que la muestra fue a conveniencia, puesto que los participantes estaban cursando una asignatura de posgrado vinculada con el tema del estudio. Sin embargo, el criterio analítico de tratamiento de los datos se llevó a cabo mediante la saturación de estos, al encontrar ideas y significados íntimamente relacionados y que son compartidos por el profesorado. 
TABLA 1

Caracterización de los participantes

\begin{tabular}{|c|c|c|}
\hline Edad & $\begin{array}{l}\text { Nivel donde imparte } \\
\text { docencia }\end{array}$ & Años de servicio \\
\hline $\begin{array}{l}\text { Menos de } 24-18 \\
\text { participantes } 25 \text { - } \\
30-35 \\
\text { participantes } 31 \text { - } \\
35-15 \\
\text { participantes } 36- \\
40-9 \\
\text { participantes } 41 \text { - } \\
45-3 \\
\text { participantes } 46- \\
50-3 \\
\text { participantes } 51 \text { - } \\
55-3 \\
\text { participantes }\end{array}$ & $\begin{array}{l}\text { Educación básica - } 63 \\
\text { Educación media superior - } \\
6 \text { Educación superior - } 16\end{array}$ & $\begin{array}{l}1-5-56 \text { participantes } 6 \text { - } \\
10-17 \text { participantes } \\
11-15-7 \text { participantes } \\
16-20-4 \text { participantes } \\
21-25-0 \\
\text { participantes } 26 \text { o más } \\
-3 \text { participantes }\end{array}$ \\
\hline
\end{tabular}

Fuente: Elaboración propia

Los datos se codificaron de la siguiente forma: la letra . que los identifica como profesores/as; las letras $E B$ que los identifica como docentes de educación básica; las letras $E M S$, que señala si pertenecen a educación media superior; y las letras $E N$, cuya referencia señala su actividad de docencia en la educación normal y $E S$, que los identifica como docentes de educación superior. El cuestionario estuvo dirigido a indagar los conceptos y significados que los participantes entendían que era la política educativa, así como sus finalidades y relaciones con el campo educativo y la pedagogía. A continuación, se presentan algunos resultados que dan cuenta centralmente sobre dichos significados y conceptos.

\section{Resultados}

Siguiendo la línea analítica expresada en el apartado anterior, a continuación, se da cuenta del análisis de los datos con base en dos elementos centrales que permiten hacer visible los significados construidos y las relaciones, visiones y perspectivas que son compartidas por el profesorado. Por un lado, una forma de elementos que no solo son materiales, sino que, a nivel simbólico, representan para cada docente lo dado en lo social, lo instituido en lo escolar y por ende, lo dictado como deseable y norma a seguir, en cierta forma, la mirada a este estado gubernamentalizado. En un segundo momento, se presentan los datos que dan cuenta de las formas en que se ha diferido, materializado, operacionalizado la política, formas que atraviesan y las acciones, pero también las subjetividades del profesorado.

\subsection{La política educativa, sus significados y elementos simbólicos: institucionalización/ gubernamentalización del espacio escolar}

Una de las cuestiones iniciales retomadas en el cuestionario aplicado al conjunto docente estuvo relacionada con la concepción que han elaborado en torno a la política educativa, si bien existieron en sus respuestas una diversidad de elementos, cada uno analizable por separado, el punto nodal que articuló todas las referencias estuvo fuertemente relacionado con la parte formal de la política educativa. Para el profesorado, la política educativa tiene que ver centralmente con una serie de ordenamientos jurídicos que invitan a pensarla desde un plano legal y, en ese sentido, bajo la lógica del imperativo educativo a cumplir, visión que deja escaso 
espacio a la interrogación de las implicaciones de esta, puesto que como aspecto formal, el grupo docente la ha incorporado como mandato casi incuestionable, en cierto sentido, un acto de gobierno mediado por los ordenamientos de orden político, un estado gubernamentalizado.

P8EB. "Son un conjunto de leyes o decretos que determinan cómo debe aplicarse la educación a nivel país, estado, municipio". (Comunicación personal, 9 de febrero de 2019)

P9EMS. "Entiendo la política educativa como el conjunto de normas o lineamientos que determinan el proceso educativo. (Comunicación personal, 9 de febrero de 2019)

P78EB. "Leyes impuestas para orientar los procesos educativos". (Comunicación personal, 9 de febrero de 2019)

P12EMS. "Compendio normativo que regula las actividades propias de la educación". (Comunicación personal, 9 de febrero de 2019)

P17EB. "Conjunto de leyes que regulan las reformas educativas". (Comunicación personal, 9 de febrero de 2019)

P35EB. "Son normas que rigen, guían aspectos relacionados con la educación". (Comunicación personal, 9 de febrero de 2019)

P53EB. "Normas que rigen la educación". (Comunicación personal, 9 de febrero de 2019)

P68EB. "Son leyes y normas que rigen a la educación". (Comunicación personal, 9 de febrero de 2019)

P73EN. "Principalmente son los fundamentos y las normas que conlleva nuestro sistema educativo y así poder regirlo". (Comunicación personal, 9 de febrero de 2019)

P52EB. "La política educativa comprende las leyes que organizan y dan sentido al sistema educativo". Comunicación personal, 9 de febrero de 2019)

P61EB. "Son las bases gubernamentales que rigen y dirigen las normas, lineamientos de la educación en nuestro país. (Comunicación personal, 9 de febrero de 2019)

Como se puede observar en los comentarios anteriores, el foco de la política educativa tiene que ver con la ley, la cual es la que rige y regula al sistema educativo, espacio que puede ser pensado desde diversas dimensiones y que se relaciona con el territorio (un país, un estado o un municipio), por otra parte, se articula con un campo de conocimiento, en este caso la educación. Dentro de ella se pueden identificar cercanamente las actividades y procesos educativos en general, los cuales son concretados en las famosas reformas educativas y escolares.

Por otra parte, para el profesorado dicha forma de regulación tiene un valor añadido, puesto que representa un elemento axiológico a seguir, en otras palabras, las leyes y los demás ordenamientos no solo ejecutaban la función de regular y regir a la educación y al sistema educativo, también lo construyen de determinada forma, en este caso desde un deber ser que se relaciona con un tipo de juicio moral de lo que es correcto y lo que no lo es, lo bueno de lo malo, lo deseable de la indeseable, en otras palabras, señalan lo político de la política y con ello su acción moralizante.

P40EB. "Son leyes, reglamentos que rigen al sistema educativo para su buen funcionamiento". (Comunicación personal, 9 de febrero de 2019)

P22EB. "Aspectos normativos para la mejora de la educación". (Comunicación personal, 9 de febrero de 2019)

P63EB. "La creación de leyes y decretos que permitan beneficiar a todos los individuos que participan en el ámbito educativo con la finalidad de mejorar la calidad de vida y bienestar futuro de las naciones". (Comunicación personal, 9 de febrero de 2019)

P75EB. "Es conocer los artículos que benefician a la educación, así como la importancia que tiene el ejercerlos y ponerlos en práctica". (Comunicación personal, 9 de febrero de 2019)

Desde esta perspectiva, no solo toca una función de regulación, sino que se plantea una finalidad que trae de fondo una idea de mejora, la cual está relacionada con un beneficio para las personas. En este sentido, la 
política educativa es un espacio donde convergen ordenamientos que buscan el progreso, desarrollo y mejora. Dichas cuestiones poseen un contenido específico que es expresado por el profesorado de la siguiente manera: P10EMS. "La entiendo como las leyes que debe cumplir la educación para lograr un fin establecido en la política, la cual debe contener también los derechos de quienes en ella participan". (Comunicación personal, 9 de febrero de 2019)

P27EB. "Política educativa es un conocimiento que se tiene acerca de las leyes establecidas para ejercer en el ámbito educativo, así como los derechos, obligaciones y responsabilidades tanto del docente como del gobierno e instituciones". (Comunicación personal, 9 de febrero de 2019)

P37EB. "Una forma de mantener lineamientos en el área de la educación, para saber los derechos y obligaciones de los maestros". (Comunicación personal, 9 de febrero de 2019)

P67EB. "Es el derecho o derechos que tienen los alumnos y también los maestros para obtener una educación de calidad y así como un trabajo digno". (Comunicación personal, 9 de febrero de 2019)

P62EB. "Herramientas que ayudan a respaldar a los estudiantes y profesores, son las normas que ayudan a la educación a respaldar a la misma". (Comunicación personal, 9 de febrero de 2019)

La política educativa, según el grupo docente, tiene que ver con la regulación por medio de leyes del espacio educativo, cuya finalidad es conseguir la mejora, traducida esta en beneficios hacia aquellos a los cuales está dirigida; dichos beneficios están relacionados con determinados derechos que los ordenamientos deben garantizar, la educación, notablemente, es uno de ellos. En uno de los comentarios, aparece un sujeto específico que se podría señalar como uno de aquellos a los cuales está dirigida la política educativa. El caso de cada docente, que tiene derechos pero también obligaciones, el matiz también está en el deber ser con respecto a la ley, entendida genéricamente como política educativa.

Por otra parte, para algunos/as docentes la política educativa no solo hace referencia al espacio macro de lo educativo, sino al aspecto más cercano de la práctica, a la propia acción escolar. En este sentido, la política educativa también organiza el espacio escolar, institucional y áulico, lo que tiene incluso que ver con las clases que imparte el profesorado.

P20EB. "Gestión que lleva a cabo leyes y normas que se rigen en una institución o aula educativa". (Comunicación personal, 9 de febrero de 2019)

P51EB. "Son las normas que rigen la educación y nos dicen cómo impartir clases". (Comunicación personal, 9 de febrero de 2019)

P58EB. "Son las leyes que vigilan la educación y su impartición". (Comunicación personal, 9 de febrero de 2019)

P13EB. "Son los lineamientos que se deben seguir en el proceso de enseñanza aprendizaje, son lineamientos diseñados por los planes de trabajo". (Comunicación personal, 9 de febrero de 2019)

$\mathrm{Si}$ bien las ideas anteriores no representan posicionamientos idénticos, se pueden colocar desde un tipo de visión o significación de la política educativa que la entiende como una serie de ordenamientos, una especie de deontología política, que bajo la idea de un deber ser dirige las acciones, rescatando una vez más una representación técnica de esta, visión que escasamente posibilita pensarla como un campo teórico de estudio. Bajo esta perspectiva, la política educativa, como acción normada de gobierno y por tanto gubernamentalizada, parece estar al centro de los significados del profesorado.

No obstante, lo anterior en todo conjunto y práctica discursiva existe dispersión. Para algunos/as docentes, los significados posibilitan una mirada menos rígida y permiten un tipo de cuestionamiento sobre lo mismo.

P41EB. "Son aquellas leyes que rigen al sistema educativo mexicano y que pueden ser modificadas de acuerdo con los tiempos". (Comunicación personal, 9 de febrero de 2019)

P49ES. "Normas y reglas que rigen la educación mediante la interpretación de estas". (Comunicación personal, 9 de febrero de 2019) 
P57EB. "Es el marco normativo que orienta las acciones que deben tomar todos los actores de la educación. Así como un espacio y momento para reflexionar acerca de resultados, problemas y posibles soluciones". (Comunicación personal, 9 de febrero de 2019)

En este espacio interpretativo y reflexivo que señala el profesorado se puede identificar una ruptura con la postura anterior, es decir, desde los primeros referentes e ideas no se había hecho mención de la posibilidad dinámica de la política, tampoco, a la acción que puede corresponder a cada docente, no solo como agente pasivo encargado de llevar a cabo e implementar la ley en las aulas, sino también posicionarse frente a esta como un sujeto capaz de interrogarla, y por tanto, también de recrearla, por lo menos desde su propio contexto; en cierto sentido, en este espacio se activa lo político, es decir, la contribución simbólica que de una $\mathrm{u}$ otra forma ejerce el profesorado a partir de sus experiencias y visiones de mundo. Sin embargo, aunque se señala esta posibilidad, la política educativa sigue estando colocada desde el espacio gubernamental, es decir, es la acción del gobierno la que puede posibilitar el cambio, puesto que es el/la docente quien se encarga de vigilar no solo su cumplimiento, sino también las innovaciones o modificaciones que esta tenga.

P77ES. "Es la forma en la que cada gobierno decide dirigir su sistema educativo, de acuerdo con la importancia y valor que le otorgue". (Comunicación personal, 9 de febrero de 2019)

P60EB. "Es el papel que toma el estado acerca de la educación y que conduce o maneja hacia un fin de lograr las mejores condiciones para el docente y alumno". (Comunicación personal, 9 de febrero de 2019)

Parece ser que la política educativa puede ser entendida también como una acción gubernamental de estado, que para el profesorado no solo implica la organización del sistema educativo, sino, como ya se había mencionado, la regulación del espacio áulico y escolar. La pregunta que surge en este punto tiene que ver, ya no tanto por la función concreta, sino más bien por aquello que regula a nivel escolar.

\subsection{Dispositivos y formas de materialización de la política: ontopolítica/biopolítica}

Si bien la ley fue uno de los principales elementos retomados por el profesorado, en este espacio analítico messose puede identificar que la acción regulatoria señalada, si bien está íntimamente relacionada con la función de docentes y estudiantes, son principalmente los documentos los que ejercen un acto de gobierno.

P30EB. "Estrategias que se utilizan en el ámbito educativo, donde se pretenden regular reformas educativas que logren favorecer el aprendizaje de los alumnos y en del profesor, las herramientas para poder lograrlo". (Comunicación personal, 9 de febrero de 2019)

P31EB. "Es el cambio de los planes y programas, a nuevas reformas, al cambio". (Comunicación personal, 9 de febrero de 2019)

P42EB. "Es la forma en que se ejecuta un modelo educativo en determinado contexto (lugar, tiempo, protocolo, etc.)". (Comunicación personal, 9 de febrero de 2019)

P48EB. "La política educativa es un fenómeno que se basa en el mejoramiento educativo con el diseño de programas". (Comunicación personal, 9 de febrero de 2019)

P64EB. "Desarrollo consecutivo que han tenido las reformas, proyectos, programas, la modificación que requiere para enriquecer o mejorar el aprendizaje de los alumnos y formación de los docentes". (Comunicación personal, 9 de febrero de 2019)

P72EB. "Es la base de la Educación en México pues es la que rige programas y planes de educación pública". (Comunicación personal, 9 de febrero de 2019)

Desde la voz del cuerpo docente, los planes y programas parecen ser el instrumento central, o como diría Foucault (2007), un dispositivo en y desde el cual se ejerce la función de gobierno del estado, función que no solo tiene que ver con ordenar lo educativo, y escolar, sino con un proceso de traducción en beneficio sobre todo para el estudiantado y el profesorado. Las reformas educativas en este marco parecen ser el objeto de transformación por antonomasia que, desde su contenido, deben garantizar el aprendizaje del conjunto estudiantil y la preparación de docentes. Dichos cambios consideran responder a una idea de desarrollo 
histórico lineal, que casi de forma natural indica a la educación (desde la política educativa) un camino a seguir como respuesta a las necesidades de actualidad del país.

P24EN. "Normas, estrategias y/o métodos que se crean y aplican en el ámbito de educación para poder obtener resultados deseados". (Comunicación personal, 9 de febrero de 2019)

P23EB. "Es un proyecto educativo que busca transformar y diseñar una propuesta educativa que permita atacar una problemática, por ello es necesario contar con un diagnóstico integral para su estructura e implementación". (Comunicación personal, 9 de febrero de 2019)

P25EB. "Las adecuaciones correctas para tener una mejora en el aprendizaje de los alumnos, así, como tener el conocimiento de lo que sí es aplicable y lo que no". (Comunicación personal, 9 de febrero de 2019)

P39EB. "Es la acción que se diseña para atender un problema que se está presentando en el ámbito educativo". (Comunicación personal, 9 de febrero de 2019)

P54EN. "Considero que son todos aquellos criterios que rigen la forma en la que se educa a las personas considerando factores como su contexto". (Comunicación personal, 9 de febrero de 2019)

P55EMS. "Creo que es el determinar qué y cómo enseñar en un país, que se debe de desarrollar en los discentes en los diferentes niveles educativos". (Comunicación personal, 9 de febrero de 2019)

Como se puede observar, esa acción de gobierno de estado focalizada a determinados fines relacionados con la mejora educativa, mejora entendida como la calidad de los aprendizajes que el estudiantado puede adquirir a lo largo de los procesos de escolarización. Si bien esta idea se encuentra en un nivel de concreción mayor al inicial, debe destacarse que la lógica sigue siendo similar, es decir, la política educativa es una estructura que ya se encuentra estructurada (gubernamentalizada) para modificar, de acuerdo con las necesidades, los planes y programas.

Otro nivel de concreción se puede encontrar en las siguientes ideas, en donde no solo se organizan las reformas traducidas en programas educativos, sino el contenido de estos, aspecto que va acercando cada vez más la política educativa al profesorado.

P16EB. "Son herramientas y métodos educativos que garantizan y perseveran una calidad en la educación y estos se cambian constantemente a los fines políticos". (Comunicación personal, 9 de febrero de 2019)

P21EB. "La calidad en cuanto a la enseñanza con implementación de nuevas estrategias, un nivel mejor de enseñanza". (Comunicación personal, 9 de febrero de 2019)

P50EB. "Para mí, la política educativa es lo que guía la enseñanza, fundamentada en teorías sociales, educativas y del desarrollo humano". (Comunicación personal, 9 de febrero de 2019)

La política educativa y su acción de regulación y gobierno también está dirigida a cuestiones más tangibles, como lo son los elementos pedagógicos y didácticos que tiene cada docente. En este sentido, no solo es un mandato de ley que incluye derechos y obligaciones, sino también es una base que sirve de fundamento para el quehacer educativo. En la política educativa, el profesorado puede encontrar las formas en que debe enseñar, es decir, el tipo ideal de práctica que debe desarrollar en las aulas y que se relaciona con cuestiones más teóricas y en cierto sentido, más cientificas.

En este marco, al parecer, una de las finalidades de la política educativa también tiene que ver con cierta garantía de calidad educativa, la cual no representa cualquier conocimiento o saber, sino aquel que es considerado válido en una determinada época y contexto. Un saber que es un universal, pues implica el espacio de llegada de todo esfuerzo de política. Bajo esta perspectiva, la política educativa es la encargada de vigilar que dichos saberes y conocimientos sean aprendidos y enseñados. Para algunos/as docentes, la política educativa también es una especie de lucha contra algo, ese algo, al parecer, está relacionado con un juego de lo que es verdadero y lo que no lo es.

P36EB. "Es la manera de saber defender y opinar sobre las necesidades de una institución". (Comunicación personal, 9 de febrero de 2019) 
P26EB. "Considero que es la base que permite al medio/ámbito educativo "regir, plantear y defender" las razones de todo aquello que nos norma en el área, de acuerdo con las necesidades y oportunidades". (Comunicación personal, 9 de febrero de 2019)

P71EB. 2Es una relación de dos temas que siempre generan conflictos, pero que de alguna manera buscan soluciones para la mejora de la sociedad". (Comunicación personal, 9 de febrero de 2019)

En estas últimas líneas se puede observar otro nivel analítico y más problemático, superando esta visión de linealidad que antecedió en la mayoría de las ideas expresadas. Linealidad que no permite pensar a la política educativa como un campo teórico y epistemológico. En estos comentarios casi finales, los participantes pudieron identificar que la política educativa tiene una fuerte relación con aspectos teóricos e incluso ideológicos. E34EB. "Un conjunto de ideologías y propuestas que intentan un régimen educativo" (Comunicación personal, 9 de febrero de 2019). Cuya verdad, posiblemente, más que estar dada de una vez y para siempre, es una dimensión que se debate y además se analiza, pues es compleja y problemática. Por tal motivo no basta una acción netamente instrumental y técnica, sino un proceder que permita la reflexión y la toma de conciencia, no solo desde el sentido común, sino a partir de principios explicativos que posibiliten la constitución del campo educativo y de la política educativa misma, vista como: P14EB. "La ciencia que se encarga de establecer las bases politicas que rigen la educación de nuestro pais" (Comunicación personal, 9 de febrero de 2019).

La política educativa, caracterizada desde esta óptica, representa un tipo de voluntad de poder en donde los sujetos, vistos como agentes, son capaces de estructurar lo estructurado y resistir al espacio gubernamentalizado, es de reconocer que, aunque en menor parte, algunos pueden dar cuenta de la acción no como sumisión o dominación, sino como estructuración de lo social, lo cual es potente si se piensa desde nuevas lógicas formativas, un tipo de formación política del profesorado que se considera necesaria en este marco.

\section{Discusión}

La formación de docentes ha sido una preocupación constante en las últimas décadas, sin embargo, lo que este trabajo ha podido visibilizar es la atención que se le ha dado a un tipo de formación en política educativa, espacio de subjetivación que supere la simple disposición de lo dado y permita constituir agentes en los lugares institucionalizados como las escuelas. La política educativa entendida desde su complejidad no puede ser un ejercicio de recitación de las leyes o incluso comprensión semántica y sintáctica de estas; requiere una reflexión analítica de esta, ejercicio que debe hacerse íntimamente relacionado con la práctica educativa llevada a cabo por el personal docente en el día a día. En otras palabras, más que dar a conocer lo que dicen las políticas, sería constituir una mirada analítica a dicho objeto, reconociendo que es, a través de sus componentes centrales, conformados en su devenir histórico, que el profesorado organiza su ejercicio, el cual, además de ser pedagógico, también es político y ético.

En este trabajo, los hallazgos muestran que los significados que se han construido principalmente se han volcado en torno a la figura de la ley, es decir, para el cuerpo docente la política educativa está constituida en leyes que disponen y organizan al sistema educativo en general. También la han relacionado con planes y programas de estudio, reformas educativas y acuerdos en general, todos dirigidos a un espacio simbólico como lo es el sistema educativo.

Lo rescatado en este texto tiene que ver precisamente con esa mirada restringida sobre lo que se entiende por política educativa, mirada que la sitúa solo desde su aspecto formal cuyo marco de acción ha despersonificado a los sujetos encargados de ejecutarla (el profesorado). En otras palabras, para el grupo docente, la política educativa se encuentra significativamente lejana a su labor y, aunque coinciden en pensar que lo que ellos desarrollan en el aula puede tener alguna relación con el tema, su posición es más bien pasiva. Desde su representación, los propósitos, contenidos, formas de enseñanza y evaluación que lleva a cabo el 
profesorado en sus instituciones son dictados por la política y a ellos les corresponde solo implementar lo dispuesto y nada más.

Lo defendido en este texto tiene que ver con este último punto, la posición del profesorado frente a la política educativa podría señalarse en los márgenes, no solo en el plano de la acción o práctica de la esta, sino en la posibilidad de pensarla de otra forma, por ejemplo, como espacio teórico-educativo. La política educativa desde la perspectiva docente está relacionada con un imperativo casi incuestionable que todo buen docente debe cumplir, pero además cuyo discurso no está dirigido a él, sino a la estructura de las instituciones, en este sentido, se podría decir de forma concreta que no hay personificación de la política, sino mera abstracción.

La política educativa parece, desde los discursos del profesorado, regir y organizar el espacio y las cosas de lo educativo y pedagógico, sin embargo, se olvida que parte de las cosas que organiza también son las personas que son sujetas a las decisiones tomadas. Si bien los participantes de este estudio mencionan que, como parte del sistema educativo, ellos también están implicados, dicha relación solo tiene que ver con un tipo de ejecución y cumplimiento de lo normado. El problema en este punto es que el grupo docente no se ha dado cuenta que lo que la política organiza no solo tiene que ver con sus formas de proceder, sino con sus subjetividades, con las ideas, representaciones y sentidos que ellos han construido acerca de lo que es ser docente, lo que implica un buen estudiante, los fines de la educación en general, etc.

En línea con lo anterior, lo que la política educativa representa, escasamente se relaciona con unas formas de pensar, donde existe un elemento tanto ontológico como epistémico de lo escolar y lo educativo. Así, se señala más bien un espacio simbólico neutro, donde lo que se dispone y presenta es confundido con formas de conocimiento científico que deben ser llevados a cabo y no cómo una serie de prácticas que están atravesadas por lo político, es decir, lógicas que están en constante tensión y conflicto, puesto que ahí se enfrentan subjetividades, identidades, visiones, intereses y creencias de los que comparte la arena de discusión educativa.

Esta forma neutra y simple de ver la política, poco ha favorecido el crecimiento del campo de la política educativa, puesto que, si lo dispuesto no está en discusión, escasamente vale la pena estudiarlo o interrogarlo, en ese sentido, su realidad está dada y casi es incuestionable. En otras palabras, la política educativa tendría que pensarse como una forma de práctica ética-política-teórica desde lo educativo. Práctica que permita interrogar las nociones y saberes que se han establecido como universales y, que, al contener también elementos ideológicos, se debe poner bajo sospecha.

\section{Conclusiones}

La política educativa es un campo de conocimiento relativamente nuevo que intenta superar la visión más técnica e instrumental que la coloca solo como un espacio procedimental y de gestión. En este texto se ha dado cuenta de su complejidad, al no solo señalar procesos sociales, sino también de un tipo de estructuración cognitiva de la realidad. En este sentido, la política educativa supera el ámbito de la factual para posicionarse como problema epistemológico y teórico.

La problemática que en este trabajo se ha desarrollado tiene que ver con los significados que el profesorado ha construido sobre la política educativa, los cuales giran en torno a ordenamientos jurídicos, planes y programas educativos, reformas escolares, técnicas y estrategias de enseñanza, aprendizaje y evaluación; no obstante, una mirada a la política educativa como campo de conocimiento supone que el escenario es más complejo de lo que parece ser.

El profesorado ubicó a la política educativa como una acción del gobierno y del estado, que emana de sus decisiones y cuyo interés central es el bien común de la población en general. En dicho horizonte discursivo el cuerpo docente ocupa un lugar más bien pasivo, pues su encomienda es seguir las disposiciones que se han constituido desde el aparato gubernamental y que al provenir de dicho espacio, representa las soluciones a los problemas sociales, políticos y económicos que el país necesita para progresar y mejorar. 
Las relaciones entre la política educativa y cada docente, se encuentran mediadas por el aspecto educativopedagógico, es decir, para los participantes, lo que los vincula con la política educativa son los documentos de política, sobre todo aquellos que implican un tipo de propuesta pedagógica, como por ejemplo los planes y programas de estudio, en donde se pueden encontrar las formas de actualidad que deben seguir las prácticas de enseñanza. Es decir, para el profesorado, su papel frente a la política educativa es de ejecutor, y el medio por el cual pueden relacionarse con ella está representado en los documentos y materiales que constituyen la parte más educativa que les toca, jugando así un papel pasivo frente a esta.

Lo que muchos de las y los docentes no reconocieron es que, frente a esa supuesta pasividad, hay toda intencionalidad y deseo de actividad. La política educativa no solo regula los materiales con lo que ellos trabajan, sino a sus conductas, y al hacerlo, no solo impacta en el plano comportamental, sino en las estructuras cognitivas más profundas que representan su subjetividad.

Cuando el profesorado no es capaz de observar lo político en la política educativa, es decir, los conflictos que en ella se encuentran aún en estado final, no da cuenta del complejo proceso de subjetivación en el que de forma consciente o inconsciente participa, y además contribuye a un tipo de reproducción simple, puesto que, dichas visiones que han sido incorporadas gracias al juego político, son llevadas a las aulas, internalizadas por sus propios estudiantes. Si bien, esto puede representar un espacio más activo de la acción política del profesorado, sigue siendo pasivo, en tanto, escasamente, identifican estos procesos o reconocen el conflicto en el plano decisional, omitiendo las sujeciones y subjetivaciones de las que son presa y más bien observando el paso de la política educativa en su labor, como mero proceso técnico-instrumental, que en su naturaleza neutra, les lleva a tomar buenas y mejores decisiones para el bienestar común de toda la población.

\section{Referencias Bibliográficas}

Aguilar, L. (2004). Recepción y desarrollo de la disciplina de política pública en México. Un estudio introductorio. Revista Sociológica, 19(54), 5-37.

Aguilar, L. (2007). La hechura de las politicas públicas. México: Porrúa.

Alarcón, J. y Donoso, S. (2018). ¿Nuevo paradigma en la política educativa chilena? Debates sobre educación y transformación social, Revista Educación, 42(2), 1-18.

Álvarez, M. (2018). La educación: compromiso esencialmente político, Revista de Investigación, 42(93), 1- 12.

Álvarez, J. (2003). Cómo hacer investigación cualitativa. Fundamentos y metodología. México: Paidós

Ávalos, M. (2013). Una mirada sobre la formación de las identidades sociales en el campo educativo. Engarces conceptuales. En O. Cruz y O. Juárez (Coord.). Politicas educativas. Sujetos y discursos hegemónicos (pp. 277-297). México: PAPDI y Plaza y Valdés

Ball, S. (1990). La gestión como tecnología moral. Un análisis ludista. En J. Ball (Comp.). Foucault y la educación. Disciplinas y poder (pp.155-168). Madrid: Morata

Bourdieu, P. (2002). Campo de poder, campo intelectual. Buenos Aires: Editorial Montressor.

Buenfil, R. (1993). Análisis de discurso y educación. México: Centro de Investigación y Estudios Avanzados del Instituto Politécnico Nacional

Buenfil, R. (2018). Laclau y la educación en América Latina: huellas de una herencia en disputa. En R. Buenfil y Z. Navarrete (Eds.). Ernesto Laclau: Apropiaciones, debates y diseminación de su pensamiento en Latinoamérica coordinado (pp.249-271). México: Ed. Plaza y Valdés

Butler, J. y Laclau, E. (2008). Los usos de la igualdad. En S. Critchley y O. Marchart. Laclau, Aproximaciones criticas a su obra (pp. 405-424). Argentina: Fondo de Cultura Económica

Carlachiani, C. (2017). Políticas públicas para la educación secundaria: entre la obligatoriedad y la inclusión, Revista Periferia, 9(1), 383-405. 
Compromiso Social por la Calidad de la Educación, (2015). Para una mejora en la autogestión escolar: análisis de los programas de la Reforma Educativa y de Escuelas de Tiempo Completo, Revista Latinoamericana de Estudios Educativos, 45(3), 11-54

Correa, E. (2011). Identidad, identificación, discurso y sujeto. Una aproximación desde el psicoanálisis y el análisis político de discurso. En R. Buenfil y Navarrete, Z. (Coord.). Discursos educativos, identidades y formación profesional. Producciones desde el análisis politico de discurso (pp. 207-226). México: PAPDI y Plaza y Valdés

Cruz, O. (2008). Las políticas educativas. Una mirada desde la traducción; En Fuentes S. y Cruz Pineda O. (Coord.) Identidades politicas y educativas (pp. 93-107). México: UPN

Cruz, O. (2011). Las políticas de formación docente y los procesos de gubernamentalidad. Una discusión sugerente. En R. Buenfil y Navarrete, Z. (Coord.). Discursos educativos, identidades y formación profesional. Producciones desde el análisis político de discurso (pp. 283-300). México: PAPDI y Plaza y Valdés.

Deleuze, G. y Guattari, F. (1994). Mil mesetas. Capitalismo y esquizofrenia. Valencia: Ed. Pre-Textos.

Fernández, A. (2018). Para pensar la educación política en la educación formal, Revista Electrónica Educare, 22(2), 302-323. doi: http://dx.doi.org/10.15359/ree.22-2.17

Flores, P. (2009). Investigación educativa y políticas públicas en México: una relación amorfa y elusiva, Revista electrónica de educación Sinéctica, 33, 1-13. Recuperado de https://bit.ly/3cSLMM2

Foucault, M. (2006). La gubernamentalidad. Seguridad, Territorio, Población. Argentina: Fondo de Cultura Económica.

Foucault, M. (2007). El nacimiento de la biopolitica. Argentina: Fondo de Cultura Económica.

Fuentes, F. (2019). Lo político y lo público en las políticas públicas. Una Perspectiva Político Discursiva. En F. Navarro (Coord.).Politicas Públicasy politicidad en educación. Configuraciones teóricas einvestigativas (pp.23-57). México: SEV

García, M. (2017). Sentidos de lo político: el activismo, lo performativo y la subversión en la memoria de mujeres en movimientos estudiantiles. México. En M. Padierna y M. García (Ed.). Lo politico en las subjetividades. Una década de investigaciones desde el Análisis Politico de Discurso (pp. 161-185). México: PAPDI y Plaza y Valdés

Giovine, R. y Suasnábar, J. (2012). Los textos legales como analizador de las políticas educativas. Consideraciones teórico- metodológicas. I Jornadas Latinoamericanas de estudios epistemológicos en Politica Educativa. Buenos Aires: RELEPE

Hernández, C. (2015). El profesorado: sujeto en construcción de las políticas educativas. En E. Treviño y J. Carbajar. (Coord.). Politicas de la subjetividad e investigación educativa (pp. 67-80). México: PAPDI y Plaza y Valdés

Juárez, J. (2014). Epistemologías de la política educativa, CPU-e Revista de Investigación Educativa, 18, 187-190

Juárez, O. (2013). Las reformas educativas: el vínculo entre lo político, la política y las políticas. En O. Cruz Pineda y O. Juárez (Coord.). Politicas educativas. Sujetosy discursos hegemónicos (pp. 27-43). México: PAPDI y Plaza y Valdés

Laboratorio Latinoamericano de Evaluación de la Calidad de la Educación (2016).Informe de Resultados del tercer Estudio Regional Comparativo y Explicativo, REICE. Revista Iberoamericana sobre Calidad, Eficacia y Cambio en Educación, 14(4), 9-32. doi: https://doi.org/10.15366/reice2016.14.4.001

Latapí, P. (2004). La política educativa del Estado Mexicano desde 1992, Revista Electrónica de Investigación Educativa, $6(2), 1-16$

Lemke, T. (2017). Introducción a la biopolitica. México: Fondo de Cultura Económica

Mainardes, J. (2015). Reflexiones sobre el objeto de estudio de la política educativa. En C. Tello (Comp.), Los objetos de estudio de la politica educativa. Hacia una caracterización del campo teórico (pp. 25-42). Buenos Aires, Argentina: EPUB.

Martínez, F. (2018). Reflexiones sobre las políticas públicas, Revista Latinoamericana de estudios Educativos, 48(2), $71-96$

Mouffe, C. (1993). El retorno de lo Político. Barcelona: Paidós. 
Navarrete, Z. (2017). Una revisión histórica del concepto identidad desde una perspectiva del Análisis Político de Discurso. En M. Padierna y M. García (Coord.). Lo politico en las subjetividades. Una década de investigaciones desde el Análisis Politico de Discurso (pp. 205-229). México: PAPDI y Plaza y Valdés

Osorio, J. (2012). Estado, biopoder y exclusión. Análisis desde la lógica del capital. México: Antropos

Padierna, M. (2017). Discursos de lo político en espacios populares. En M. Padierna y M. García (Coord.). Lo político en las subjetividades. Una década de investigaciones desde el Análisis Politico de Discurso (pp. 149-160). México: PAPDI y Plaza y Valdés

Popkewitz, T. (1994). Política, conocimiento y poder: algunas cuestiones para el estudio de las reformas educativas. Revista de Educación. (305), 103- 137

Popkewitz, T. (1997). Sociología politica de las Reformas Educativas. Madrid: Morata.

Popkewitz, T. (1998). La conquista del alma infantil. Política de escolarización y construcción del nuevo docente. Barcelona: Pomares

Popkewitz, T. y Brennan, M. (2000). Reestructuración de la teoría social y política en la educación: Foucault y una epistemología social de las prácticas escolares. En T. Popkewitz y M. Brennan (Comp.). El desafío de Foucault, (pp. 17- 52). Barcelona: Pomares- Corredor

Popkewitz, T. (2009). El cosmopolitismo y la era de la reforma escolar. Madrid: Morata

Razo, A. (2018). La Reforma Integral de la Educación Media Superior en el aula: política, evidencia y propuestas, Perfiles educativos, 40(159), 90-106

Sorrentino, V. (2012). Biopolítica, liberalismo y libertad en Foucault. En D. Fernández y Sierra, A. (Eds.) La biopolítica en el mundo actual. Reflexiones sobre el efecto Foucault. Barcelona: Laertes

Tello, C. (2015). Los objetos de estudio de la política educativa. Tres argumentaciones epistemológicas para su análisis. En C. Tello (Coomp.) Los objetos de estudio de la politica educativa. Hacia una caracterización del campo teórico, (pp. 43-62). Buenos Aires, Argentina: EPUB

Treviño, E (2013). La noción de lo político y el estudio de las políticas educativas. Congreso Nacional de Investigación Educativa. Ponencia llevada a cabo en el Congreso del Consejo mexicano de Investigación Educativa (COMIE). Guanajuato, México

Treviño, E. (2015). La educación Superior y el advenimiento de la sociedad del conocimiento. México: Biblioteca de la Educación Superior/ANUIES.

Treviño, E. y Tolentino, M. (2017). El lugar de lo político en el discurso de las políticas públicas. Andamios, 14(35), 9-121. 